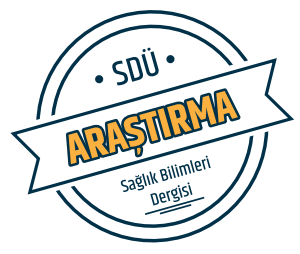

Sdü Sağlık Bilimleri Enstitüsü Dergisi / Cilt 8 Sayı 3 / 2017

\title{
Öğrenme Ortamı Olarak Huzurevi: Öğrenci Gözü ile Değerlendirme
}

\author{
A pilot Study: Student Nurses' Perceptions About Nursing Home As A \\ Learning Environment
}

Fatoş Korkmaz ${ }^{1}$, Imatullah Akyar', Nilay Ercan Şahin ${ }^{1}$

${ }^{1}$ Hacettepe Üniversitesi Hemşirelik Fakültesi, Ankara, Türkiye.

\section{Özet}

Amaç: Sağlık personelinin artan yaşlı nüfus hizmetin gereksinimini karşılayacak yeterliliğe, bilgi ve beceriye sahip olması eğitimleri sırasında yaşlı birey ile çalışmaları ile mümkün olmaktadır. $\mathrm{Bu}$ araştırma öğrenme ortamı olarak huzurevi uygulamalarının hemşirelik öğrencilerinin gözüyle değerlendirilmesi ve yaşlıya yönelik tutumları ile değerlendirmeleri arasındaki ilişkinin tanımlanması amacıyla gerçekleştirilmiştir.

Materyal-Method: Tanımlayıcı nitelikteki araştırma bir üniversitenin son sınıf hemşirelik öğrencileri ile yapılmıştır. Tüm evrene (n:82) ulassılması hedeflenen araștırmada tanıtıcı bilgiler formu, Klinik Öğrenim Çevresi Ölçeği (puan aralığı 22-110, puan arttıkça değerlendirme olumlu), Yaşlilara Yönelik Tutum Ölçeğinden (puan arttıkça tutum olumlu) oluşan veri toplama araçları e-posta yolu ile öğrencilere iletilmiş ve araştırma formları cevaplayan 22 öğrenci ile tamamlanmıştır.

Bulgular: Öğrenciler Klinik Öğrenim Çevresi Ölçeğinden ortalama $68.59 \pm 6.59$ puan, Yașlilara Yönelik Tutum Ölçeğinden 163.40 \pm 20.77 (olumlu alt boyut $82.77 \pm 13.05$; olumsuz alt boyut $80.63 \pm 12.43$ ) almıştır.

Sonuç: Öğrencilerin öğrenme ortamı olarak huzurevi değerlendirmeleri ve yaşlılığa yönelik tutumları olumlu ya da olumsuz bulunmamıştır.

Anahtar kelimeler: Hemşirelik Öğrencisi, Huzurevi, Klinik Ortam

\begin{abstract}
Objective: Population ageing led increase in demand on health care services and healthcare professionals. To prepare students for future, assessment of perceptions about nursing homes as a learning environment and elderly is essential. This descriptive study aimed to evaluate nursing students' perceptions about nursing home as a learning environment and the relationship between attitudes towards elderly and nursing home clinical environment assessment.
\end{abstract}

Material-Method: Students (n:82) enrolled and completed their clinical placement in public health nursing course in one university in Ankara/Turkey, in the spring term of 2015-2016 academic year were targeted, of them 22 students accepted to take part in the study. Students were informed and invited to study via email. Data were collected with socio-demographic form, Clinical Learning Environment Scale and Kogan's Scale of Attitudes Towards the Elderly.

Results: Students' clinical learning environment scale mean score was $68.59 \pm 6.59$ and, the Kogan's Scale of Attitudes towards the Elderly total score was $163.40 \pm 20.77$. The subscale score for positive attitudes to elderly was $82.77 \pm 13.05$ and for negative attitudes was $80.63 \pm 12.43$.

Conclusions: Students evaluated their clinical learning environment in nursing homes as neither positive nor negative as well as their attitudes towards elderly.

Keywords: Nursing Student, Nursing Home, Clinical Environment

\section{Giriş}

Günümüzde tüm dünyada ve ülkemizde yaşlı popülasyonun artması $(1,2)$ ile sağlık hizmetlerinden yararlanan yaşlı nüfus sayısı artış göstermekte, yaşlı birey ve ailesine evinde ya da kurumda hizmet sunacak sağlik personeline gereksinim duyulmaktadır (3).

Sağlık personelinin artan bu gereksinimini karşılayacak yeterliliğe, bilgi ve beceriye sahip olması ve geriatri alanına ilgi duyması beklenmektedir (4). Amerika Ulusal Geriatri Hemşireleri Birliği hemşirelik program müfredatlarında geriatri ve gerontoloji konularının teorik ve uygulamalı saatler ile zorunlu olarak yer verilmesi gerektiğini belirtmektedir (5). Dünya Sağlık Örgütü de geriatri ve gerontoloji alanı eğitiminde öğrencilerin yaşlı bireyin bakımında yaşla birlikte değişen gereksinimlerine yanıt verme yeteneğini geliştirme, alana özel bilgi ve becerilerini uygulamaya aktarmalarını sağlamada ileri eğitimsel deneyimleri yaratıcı bir eğitim çevresi ile kazanılacağını vurgulamaktadır (6).

Eğitimleri sırasında öğrenciler çoğunlukla klinikle çok bağlantılı olmadığının düşünülmesi ve eğitimde sıklıkla teknik becerilere daha çok odaklanılması nedeniyle klinik uygulama alanları arasında yaşlı bireye hizmet veren 
kurumlara çok fazla yer verilmemektedir (7). Yaşlı bireye yönelik teorik eğitimin verildiği iç hastalıkları ve halk sağlı̆̆ hemşireliği derslerinde kliniklerde yaşlı birey ile çalışma deneyiminin dışında sıklıkla huzurevleri geriatri alanına özel hemşirelik bakım becerilerine yönelik öğrenme ortamı olarak kullanılmaktadır $(8,9)$. Bu ortamlarda öğrenciler enfeksiyon kontrolü, beslenme takibi, fiziksel muayene, ilaç uygulamaları, öz bakım gereksinimlerinin karşılanması gibi temel hemşirelik uygulamalarının yanı sıra iletişim becerileri, sosyal aktivite planlama, bakım verilen bireyi aile ve yakınları ile ele alma, yaşam sonu bakım, bakımda bireyi değerlendirme, izleme gibi uygulamaları gerçekleştirme ve kurumsal hizmetler ile hemşirelik hizmetlerini gözleme firsatı bulmaktadır (8-10).

Literatürde, hemşirelik öğrencilerinin klinik uygulamaya yönelik düşünceleri ve kaygı düzeyleri ile farklı kliniklerin öğrenme deneyimi üzerine etkisini inceleyen çalışmalar vardır. $\mathrm{Bu}$ çalışmalar incelendiğinde uygulama alanında öğrencilerin öğrenme deneyiminin çok önemli olduğu ve kariyer planlamalarına yön verdiği ifade edilmektedir (1112). Uygulama alanları; öğrenci, sağlık ekibinin üyeleri, sağlık hizmeti alan birey, yakınları, öğretim elemanı gibi pek çok değişkeni içermektedir. Bu ortamlara ilişkin etkin planlamanın yapılamaması öğrenci ve öğretim elemanı açısından zor ve stresli uygulama deneyimine neden olabilmektedir (13-14).

Uluslararası literatürde yapılan huzurevi ortamının öğrenme ortamı olarak değerlendirildiği çalışmalarda hemşirelik öğrencilerinin olumlu ve olumsuz öğrenme deneyimlerinin olduğu, deneyimlerinin kurumda çalışan personel, kaynakların yetersizliği, öğretim elemanı eksikliği ile yaşlılığa yönelik tutumlarından etkilenebileceği üzerinde durulmaktadır (10,15-18). Ülkemizde ise hemşirelik öğrencilerinin klinik öğrenme yaşantılarına ilişkin yapılan çalışmalar genellikle hastane ortamına odaklanmış olup huzurevi ve yaşlıya hizmet sunan alanlara ilişkin değerlendirmenin yapıldığı çalışma bulunmamaktadır. Bu çalışma, hemşirelik öğretiminde, klinik uygulama alanlarına ilişkin yapılacak iyi bir düzenlemenin öğrencilerin hemşirelik bilgi/ becerisinin gelişmesine, sağlık ekibinin diğer üyeleri ile etkileşmesine, özgüvenlerinin artmasına, kariyer planlamasına ve mesleki hazır oluşluğa olumlu katkılar sağladığı göz önünde $(14,19)$ bulundurularak öğrenme ortamı olarak huzurevi uygulamalarının öğrenci gözüyle değerlendirilmesi amacıyla gerçekleştirilmiştir.

\section{Materyal-Method}

Araştırma, tanımlayıcı olarak Mayıs -Haziran 2016 tarihinde Hacettepe Üniversitesi Hemşirelik Fakültesi'nde yapılmıştır.

Araştırmanın evrenini 2015-2016 öğretim yılı bahar döneminde Halk Sağlığ Hemşireliği dersine devam eden ve klinik uygulamalarını tamamlayan toplam 82 öğrenci oluşturmuştur. Çalışmada örneklem seçimi yapılmamış, tüm öğrencilere ulaşılması hedeflenmiş ancak 22 öğrenci araştırmaya katılmıştır.

Araştırma verileri öğrencilerin huzurevi uygulaması tamamlanmasının ardından final sınavlarının bitiminden sonra gerçekleştirilmiştir. Online ortamda oluşturulan veri toplama formları öğrencilere araştırma hakkında bilgi ve davet ile birlikte eposta yolu ile ulaştırılmıştır. Çalışmaya katılmayı kabul eden öğrenciler online veri toplama formlarını doldurmuştur.

Tablo 1. Öğrencilerin Sosyo-Demografik Özellikleri (n: 22)

\begin{tabular}{|c|c|c|}
\hline Özellikler & $\mathbf{n}$ & $\%$ \\
\hline \multicolumn{3}{|c|}{ Yaș $23.3 \pm 0.56(\min .22-\max .24)$} \\
\hline 22 & 1 & 4.5 \\
\hline 23 & 13 & 59.1 \\
\hline 24 & 8 & 36.4 \\
\hline \multicolumn{3}{|l|}{ Cinsiyet } \\
\hline Kadın & 20 & 90.9 \\
\hline Erkek & 2 & 9.1 \\
\hline \multicolumn{3}{|l|}{ Medeni Durum } \\
\hline Bekar & 21 & 95.5 \\
\hline Evli & 1 & 4.5 \\
\hline \multicolumn{3}{|c|}{ Annenin Eğitim Düzeyi } \\
\hline İlkokul & 15 & 68.2 \\
\hline Ortaokul & 4 & 18.2 \\
\hline Lise & 3 & 13.6 \\
\hline \multicolumn{3}{|c|}{ Babanızın Eğitim Düzeyi } \\
\hline İlkokul & 8 & 36.4 \\
\hline Ortaokul & 7 & 31.8 \\
\hline Lise & 2 & 9.1 \\
\hline Lisans & 5 & 22.7 \\
\hline \multicolumn{3}{|l|}{ Şu an Yaşadığı Yer } \\
\hline Ailesi ile & 10 & 45.5 \\
\hline Yurtta & 7 & 31.8 \\
\hline Evde & 5 & 22.7 \\
\hline \multicolumn{3}{|c|}{ Ailede Halen Birlikte Yaşı ı ile } \\
\hline \multicolumn{3}{|c|}{ Yaşama Durumu } \\
\hline Evet & 7 & 31.8 \\
\hline Hayır & 15 & 68.2 \\
\hline \multicolumn{3}{|c|}{ Büyükanne ve Büyükbaba Sağ } \\
\hline \multicolumn{3}{|c|}{ Olma Durumu } \\
\hline Anneanne sağ & 14 & 63.6 \\
\hline Babaanne sağ & 10 & 45.5 \\
\hline Dede (anne) & 7 & 31.8 \\
\hline Dede (baba) & 5 & 22.7 \\
\hline \multicolumn{3}{|c|}{ Mezun Olduğunda Yaşlıya Hizmet } \\
\hline \multicolumn{3}{|c|}{ Veren Kurumda Çalışmayı İsteme } \\
\hline Evet & 13 & 59.1 \\
\hline Hayır & 9 & 40.9 \\
\hline \multicolumn{3}{|c|}{ Hemşirelik Mesleğini Seçme } \\
\hline \multicolumn{3}{|c|}{ Nedeni } \\
\hline Mesleği sevme & 8 & 36.4 \\
\hline Sağlık alanına ilgi & 7 & 31.8 \\
\hline İşimkanı & 3 & 13.6 \\
\hline Aile yönlendirmesi & 2 & 9.1 \\
\hline Puanı yettiği için & 2 & 9.1 \\
\hline
\end{tabular}

Araştırmanın verileri Tanıtıcı Bilgiler Formu, "Klinik Öğrenim Çevresi Ölçeği” ve "Yaşlilara Yönelik Tutum Ölçeği" ile toplanmıştır. "Tanıtıcı Bilgiler Formu", öğrencilerin sosyo-demografik özelliklerini belirlemek 
amacıyla toplam 10 sorudan oluşmaktadır. "Klinik Öğrenim Çevresi Ölçeği" öğrencilerin uygulama ortamlarını değerlendirmek üzere Dunn ve Burnett tarafindan 1995 yılında geliştirilmiştir. Ölçeğin Türkçe adaptasyonu Sarı tarafindan 2001 yılında hemşirelik öğrencileri ile yapılmıştır (iç tutarlılık sayısı 0.79). Ölçek 22 madde ve 5 alt boyuttan oluşmaktadır. Ölçek alt boyutları personel öğrenci ilişkileri, öğretim elemanının sorumlulukları, hasta ilişkileri, öğrenci memnuniyeti, hiyerarşi ve rutinlerdir. Ölçekten alınacak puan aralığı 22-110'dur ve puan arttıkça uygulama ortam değerlendirmesi olumlu olmaktadır. "Yaşlılara Yönelik Tutum Ölçeği” Kogan tarafından yaşlılara yönelik tutumları ölçmek amacıyla geliştirilmiştir. Ölçek olumlu ve olumsuz tutumları yansıtan 34 maddeden oluşan iki boyuta sahiptir. Ölçeğin Türkçe geçerlilik-güvenirliği Duyan ve Gelbal tarafından 2013 yılında üniversite ögrrencileri ile yapılmış, iç tutarlık katsayıs1 0.84 olarak bulunmuştur (olumlu tutum alt boyutu 0.78, olumsuz alt boyutu 0.79).

Veriler IBM SPSS Statistics v23 programında analiz edilmiştir. Araştırmada tanımlayıcı istatistikler (sayı, yüzde, ortalama, standart sapma) kullanılmıştır.

Araştırmanın gerçekleştirilmesi için kurumdan yazılı izin ve etik kurul izni (GO 16/145-39) alınmıştır.

Tablo 2. Öğrencilerin Klinik Öğrenim Çevresi Ölçeği ve Yaşlılara Yönelik Tutum Ölçeği Puan Dağılımları (n:22)

\begin{tabular}{lc}
\hline Özellikler & $\mathbf{X} \pm \mathbf{S S}$ \\
\hline Klinik Öğrenim Çevresi Ölçeği & \\
\hline Personel öğrenci ilişkileri (6-30) & $18.68 \pm 3.06$ \\
\hline Öğretim elemanının sorumlulukları (4-20) & $12.31 \pm 1.98$ \\
\hline Hasta ilişkileri (4-20) & $13.04 \pm 2.01$ \\
\hline Öğrenci memnuniyeti (4-20) & $12.90 \pm 2.38$ \\
\hline Hiyerarşi ve rutinler (4-20) & $11.63 \pm 1.98$ \\
\hline Ölçek toplam puan (22-110) & $68.59 \pm 6.59$ \\
\hline Klinik Öğrenim Çevresi Ölçeği & \\
\hline Olumlu Tutum (17-119) & $82.77 \pm 13.05$ \\
\hline Olumsuz Tutum (17-119) & $80.63 \pm 12.43$ \\
\hline Ölçek toplam puan (34-238) & $163.40 \pm 20.77$ \\
\hline
\end{tabular}

\section{Bulgular}

Öğrencilerin \%59.1'i 23 yaşında (Min:22-Max:24), \%90.9'u kadın, \%95.5'i bekar, \%45.5'i ailesi ile birlikte yaşamakta, \%68.2'sinin annesi, \%36.4'ünün babası ilkokul mezunudur. Öğrencilerin \%31.8'i halen yaşlı bir aile büyüğü ile yaşamakta, $\%$ 63.6'sının anneannesi, \%45.5'inin babaannesi, \%31.8 ve $\% 22.7$ 'sinin dedesi sağ olup \%59.1'i mezuniyet sonrası yaşlı bireye bakım hizmeti veren bir kurumda çalışabileceğini belirtmiștir. Katılımcıların \%36.4'ünün hemşirelik mesleğini sevdiği için, \%31.8'inin sağlıkla ilgili bir alan olduğu için hemşirelik bölümünü tercih ettiği bulunmuştur (Tablo 1).

Öğrenciler klinik öğrenim çevresi tutum ölçeğinden toplam
$68.59 \pm 6.59$, yaşlilara yönelik tutum ölçek toplam puanları ise $163.40 \pm 20.77$ 'dir. Öğrencilerin personel öğrenci ilişkilerini (18.68 \pm 3.06$)$, hasta ilişkilerini (13.04 \pm 2.01$)$ ve öğrenci memnuniyeti $(12.90 \pm 2.38)$ alt boyutlarını; öğretim elemanının sorumlulukları $(12.31 \pm 1.98)$ ve hiyerarşi ve rutinler $(11.63 \pm 1.98)$ alt boyutlarına göre daha olumlu değerlendirmişlerdir (Tablo 2).

Tablo 3. Öğrencilerin Sosyo-Demografik Özelliklerine Göre Klinik Öğrenim Çevresi Ölçeği ve Yaşl1lara Yönelik Tutum Ölçeği Puan Dağılımları (n:22)

\begin{tabular}{|c|c|c|c|c|}
\hline \multicolumn{2}{|c|}{$\begin{array}{l}\text { Sosyo-Demografik } \\
\text { Özellikler }\end{array}$} & \multirow{3}{*}{$\begin{array}{l}\text { Klinik } \\
\text { Öğgrenim } \\
\text { Çevresi } \\
\text { Ölçeği } \\
\\
\qquad \\
\qquad \pm \text { SS }\end{array}$} & \multicolumn{2}{|c|}{$\begin{array}{c}\text { Yaşlılara Yönelik Tutum } \\
\text { Ölçeği }\end{array}$} \\
\hline & $\mathbf{n}$ & & $\begin{array}{c}\text { Olumlu } \\
\text { Tutum }\end{array}$ & $\begin{array}{c}\text { Olumsuz } \\
\text { Tutum }\end{array}$ \\
\hline & & & $\mathbf{X} \pm \mathbf{S S}$ & $\mathbf{X} \pm \mathbf{S S}$ \\
\hline \multicolumn{5}{|l|}{ Yaş } \\
\hline $\begin{array}{l}23 \text { ve alt } 1 \\
24\end{array}$ & $\begin{array}{c}14 \\
8\end{array}$ & $\begin{array}{l}68.30 \pm 7.09 \\
69.62 \pm 6.30\end{array}$ & $87.30 \pm 7.34$ & $83.84 \pm 8.29$ \\
\hline \multicolumn{5}{|l|}{ Cinsiyet } \\
\hline $\begin{array}{l}\text { Kadın } \\
\text { Erkek }\end{array}$ & $\begin{array}{c}20 \\
2\end{array}$ & $\begin{array}{l}69.2 \pm 6.59 \\
62.5 \pm 2.12\end{array}$ & $\begin{array}{l}82.5 \pm 13.41 \\
85.5 \pm 12.02\end{array}$ & $\begin{array}{r}80.75 \pm 12.61 \\
79.5 \pm 14.84\end{array}$ \\
\hline \multicolumn{5}{|c|}{ Anne Eğitim Düzeyi } \\
\hline $\begin{array}{l}\text { İlkokul } \\
\text { Ortaokul ve } \\
\text { Lise }\end{array}$ & 15 & $67.00 \pm 6.30$ & $85.00 \pm 13.98$ & $83.73 \pm 10.37$ \\
\hline \multicolumn{5}{|c|}{ Baba Eğitim Düzeyi } \\
\hline $\begin{array}{l}\text { İlkokul } \\
\text { Ortaokul } \\
\text { Lise ve Lisans }\end{array}$ & $\begin{array}{l}8 \\
7 \\
7\end{array}$ & $\begin{array}{c}66.87 \pm 7.37 \\
70.14 \pm 11.47 \\
69.00 \pm 8.38\end{array}$ & $\begin{array}{c}84.25 \pm 18.81 \\
82.57 \pm 10.62 \\
81.28 \pm 8.07\end{array}$ & $\begin{array}{c}85.00 \pm 9.94 \\
78.28 \pm 18.31 \\
78.00 \pm 7.11\end{array}$ \\
\hline
\end{tabular}

Ailede Birlikte Yaşanılan Yaşı Olma Durumu

\begin{tabular}{lcccc} 
Evet & 7 & $70.14 \pm 7.96$ & $80.28 \pm 18.24$ & $75.57 \pm 16.13$ \\
Hayır & 15 & $67.86 \pm 6.02$ & $83.93 \pm 10.41$ & $83.00 \pm 10.08$ \\
\hline
\end{tabular}

Büyükanne ve Büyükbaba Sağ Olma Durumu

\begin{tabular}{lcccc}
\hline Anneanne sağ & 14 & $67.69 \pm 7.08$ & $84.92 \pm 14.76$ & $83.30 \pm 9.15$ \\
Babaanne sağ & 10 & $66.55 \pm 7.10$ & $79.22 \pm 19.00$ & $77.55 \pm 15.18$ \\
Dede (anne) & 7 & $67.71 \pm 4.53$ & $85.42 \pm 10.39$ & $86.42 \pm 12.46$ \\
Dede (baba) & 5 & $70.00 \pm 7.58$ & $78.60 \pm 7.86$ & $77.00 \pm 6.08$
\end{tabular}

Mezun Olduğunda Yașlıya Hizmet Veren Kurumda Calıșmayı İsteme

\begin{tabular}{|c|c|c|c|c|}
\hline Evet & 13 & $67.46 \pm 4.66$ & $81.15 \pm 15.62$ & $79.76 \pm 15.55$ \\
\hline Hayır & 9 & $70.22 \pm 8.74$ & $85.11 \pm 8.41$ & $81.88 \pm 6.35$ \\
\hline \multicolumn{5}{|c|}{ Hemşirelik Mesleğini Seçme Nedeni } \\
\hline Mesleği sevme & 8 & $71.12 \pm 7.14$ & $79.25 \pm 18.39$ & $86.00 \pm 11.16$ \\
\hline $\begin{array}{l}\text { Sağlık alanına } \\
\text { ilgi }\end{array}$ & 7 & $67.00 \pm 7.95$ & $87.28 \pm 9.30$ & $83.85 \pm 7.51$ \\
\hline İş imkanı & 3 & $71.5 \pm 2.12$ & $85.50 \pm 2.12$ & $76.50 \pm 4.94$ \\
\hline $\begin{array}{l}\text { Aile } \\
\text { yönlendirmesi }\end{array}$ & 2 & $67.66 \pm 1.52$ & $80.66 \pm 13.65$ & $78.33 \pm 4.04$ \\
\hline $\begin{array}{l}\text { Puan1 yettiği } \\
\text { için }\end{array}$ & 2 & $62.50 \pm 2.12$ & $81.50 \pm 6.36$ & $55.50 \pm 19.09$ \\
\hline
\end{tabular}


Öğrencilerin yaşlılığa yönelik tutum ölçeği olumlu tutum alt boyutundan $82.77 \pm 13.05$ ve olumsuz tutum alt boyutundan $80.63 \pm 12.43$ puan almışlardır. Öğrencilerin yaşlı bireye yönelik olumlu tutumlarının daha yüksek olduğu görülmektedir (Tablo 2).

23 yaş ve altı, erkek, annesi ve babası ilkokul mezunu, ailesinde yaşlı ile birlikte yaşamayan, anneannesi ve dedesi sağ, mezun olduğunda yaşliya hizmet veren kurumda çalışmayı istemeyen ve sağlık alanına ilgi duyarak hemşirelik mesleğini tercih eden öğrenciler yaşlı bireye yönelik olumlu tutuma sahipken, bu öğrencilerin klinik öğrenim çevresi değerlendirmeleri ise daha olumsuzdur (Tablo 3).

\section{Tartışma}

Öğrenme ortamı olarak huzurevi uygulamalarının, öğrenci gözüyle değerlendirilmesi amacıyla gerçekleştirilen bu çalışmada; öğrencilerin klinik öğrenim çevresine ilişkin tutumlarının orta düzeyde (ne olumlu ne de olumsuz) olduğu bulunmuştur. Diğer taraftan öğrencilerin, öğrenme ortamında hizmet alan yaşlılara yönelik tutumlarının olumlu olduğu saptanmıştır.

Öğrencilerin yaşliya ve bu kapsamda yaşlı ile bir araya geldikleri ortamlar olan yaşlı bakım merkezleri ve huzurevlerine ilişkin değerlendirme sonuçları farklılık göstermektedir. Çalışma sonuçları öğrencilerin genel anlamda yaşlının bakım aldığı alanlar ve huzurevlerindeki öğrenme ortamına ilişkin daha çok olumlu yönde $(10,20)$ bir değerlendirme yaptıkları ancak sınırlı da olsa olumsuz değerlendirmelerinin $(7,21)$ de olduğunu göstermektedir. $\mathrm{Bu}$ çalışmada öğrencilerin genel olarak öğrenme ortamı bakış açısı ile huzurevlerine ilişkin değerlendirmeleri orta düzeyde bulunmuştur. Elde edilen bu bulgunun öğrencilerin huzurevi uygulama süresi ile ve çalışmaya katılan öğrenci sayısının sınırlılığı ile ilgili olduğu düşünülebilir. Bununla birlikte huzurevlerindeki öğrenme sürecinde uygulama alanından en olumlu katkının alınabilmesi için sürecin profesyonelce planlanması ve yönetilmesinin de önemli olduğu vurgulanmıştır (20). Gerek teknoloji gerekse sağlık alanındaki gelişmelere paralel olarak yaşam süresinin uzaması ile sağlık profesyonellerine eğitimleri sırasında daha yapılandırılmış öğrenme ortamlarının ayarlanması $(19,21)$ ve bu yolla öğrencilerin yaşlıya ilişkin deneyimlerinin artırılması önem kazanmaktadır.

Diğer taraftan ölçeğin alt boyut puan ortalamalarının dağılımında "personel öğrenci ilişkileri" alt boyut puan ortalamasının en yüksek olduğu, sonrasında "hasta ilişkileri”, “öğrenci memnuniyeti” ve “öğretim elemanının sorumlulukları" alt boyut puan ortalamalarının sıralandığ bulunmuştur. Öğrenme ortamı olarak huzurevlerindeki öğrenim sürecinin; iyi düzenlenmesi ve yapılandırılması kazanılacak olumlu deneyimler açısından ne kadar önemli ise $(19,21)$ bu ortamda birlikte çalıştığı ve gözlemlediği profesyoneller ile iletişimi de o kadar önemlidir. Huzurevleri öğrenme ortamı olarak değerlendirildiğinde, öğretim elemanın öğrenme ortamının bir parçası olarak görülmemesi dolayısı ile puan ortalamasının diğer alt boyut ortalamalarına göre düşük olması beklenilen bir sonuç olarak yorumlanabilir.
Ülkemizde öğretim elemanlarının daha çok öğrenci için uygun alanların seçiminde ve yazışma sürecinde daha aktif rol aldı $\breve{g}_{1}$ öğrenme ortamın içinde çok da yer alamadığı görülmektedir. Diğer taraftan öğrenme ortamında ilk ve bazen tek profesyonel iletişim kurulan ve öğrenme ortamında öğrencinin asıl destek aldığı bireyler olan huzurevi çalışanlarını içeren alt boyut puan ortalamasının yüksek olması öğrencilerin olumlu bir öğrenme için huzurevi çalışanları ile ilk basamakta kurması gereken iletişimi başlatabildiklerini göstermektedir. Öğrenciler ile özellikle huzurevi çalışanları ve hastalar arasındaki iletişim güçlendikçe öğrenme deneyimlerinin olumlu yönde $\operatorname{arttığg~(22)~düşünüldüğünde~elde~edilen~bu~}$ bulgunun istenilen yönde olduğu söylenilebilir.

Öğrencilerin yaşlılığa yönelik tutum ölçeğinden aldıkları puan ortalamalarının dağılımına bakıldığında yaşlıya yönelik olumlu tutum puanlarının daha yüksek olduğu görülmektedir. Yaşlı nüfus oranı hızla artan bir toplumda genç bir grubun ifade ettiği bu bulgu oldukça memnun edicidir. Bununla birlikte elde edilen bu bulgunun içinde yaşadığımız kültürün aile büyükleri ya da yaşılı bireylere yönelik sahiplenme, saygı duyma, kabullenme ve ihtiyaç halinde bakım verme ile ilgili öğretilerine uyumlu bir sonuç olduğu söylenebilir. Diğer yandan literatürde yaşlılık ve yaşlıya ilişkin öğrencilerin olumsuz bir tutumun olmadığını ancak öğrenme sürecinde bu duygunun değişebileceğini göstermektedir (23).

Öğrencilerin yaşlıya yönelik olumlu tutumları olmasına rağmen daha çok yaşlı bireylerin yaşam alanı ya da bakım gördüğü alanlar olan huzurevlerine, bir öğrenme ortamı olarak olumsuz değerlendirmelerinin $(7,21)$ hem toplumun genelinin hem de yaşlının huzurevlerine ilişkin çokta olumlu olmayan bakış açısından köken aldığı düşünülebilir. Çünkü yaşlanma ve yalnız olarak yaşamını devam ettirme şansı olmayan bireylerin öncelikli tercihi çocukları ile birlikte yaşamak ve onlardan ihtiyaç durumunda bakım almaktır (4). Yaşlının bu beklentisi yetiştirilirken bu yaklaşımı benimseyen (birlikte yaşanılan yaşlı aile üyelerinin varlığı ya da ailenin yaşlıya yönelik öğretileri), kız ya da erkek çocuklar tarafından da kabul edilmektedir. Bu yaklaşım yaşlıların, (ebeveynler) evde ailenin büyük çocukları tarafından ya da varsa erkek evlat tarafindan bakılması ile ilgili beklentisinden ya da ailenin yaşlısının huzurevinden bakımı için gerekli ekonomik refahta olmamasından köken aldığı söylenebilir. Öğrencilerin ailede kazandıkları bu yaklaşım huzurevlerindeki öğrenme ortamından etkilenebilmektedir.

\section{Sonuç}

Öğrenme ortamı olarak huzurevi uygulamalarının, öğrenci gözüyle değerlendirilmesi ve öğrencilerin yaşlıya yönelik tutumlarını belirlemek amacıyla gerçekleştirilen bu çalışmada; öğrencilerin öğrenim çevresi olarak değerlendirdikleri huzurevlerine ilişkin tutumlarının orta düzeyde (ne olumlu nede olumsuz) ve bu ortamda bakım alan yaşliya yönelik olumlu tutumlarının daha fazla olduğu sonucuna varılmıştır. Öğrenci sayısının daha fazla olduğu, karşılaştırmalı ve alana özgü ölçüm araçları ile çalışmaların yapılması önerilmektedir. 


\section{Kaynakça}

1. Nüfus ve Demografi [internet]. Türkiye İstatistik Kurumu [Erişim: 20 Şubat 2016]. http://www.turkstat.gov.tr/UstMenu. do?metod=temelist.

2. Akgun S, Bakar C, Budakoglu I. Trends of Elderly Population in the World and Turkey: Problems and Recommendations, Turkish Journal of Geriatrics 2004; 7(2):105-110.

3. Sağlık Araştırması 2012 [internet]. Türkiye İstatistik Kurumu [Erişim:20 Şubat 2016] http://www.tuik.gov.tr/ Kitap.do?metod=KitapDetay\&KT_ID=1\&KITAP_ID=223.

4. Erdem M. Yaşlıya bakım verme. Anadolu Hemşirelik ve Sağlık Bilimleri Dergisi 2008; 11(4):101-106.

5. Thornlow D, Latimer D, Kingsborough J, Arietti L. Caring for an Aging America: A Guide for Nursing Faculty. AACN [Internet]. Johns Hartford Foundation [Cited: 2016 Feb 20]. Available from: http:/www.aacn.nche.edu/geriatric-nursing/ monograph.pdf

6. WHO European Strategy for Continuing Education for Nurses and Midwives [Internet], World Health Organization Europe Gerontological Nursing Curriculum 2003 [Cited: 2016 Feb 20]. Available from:http://www.euro.who.int/ data/assets/pdf_file/0005/125744/E72918.pdf

7. Bjork IT, Bernsten K, Brynildsen G, Hestestun M. Nursing students' perceptions of their clinical learning environment in placements outside traditional hospital settings. Journal of Clinical Nursing 2014; 23:2958-2967.

8. Papp I, Markkanen M, von Bonsdorff M. Clinical environment as a learning environment: student nurses' perceptions concerning clinical learning experiences. Nurse Education Today 2003; 23: 262-268.

9. Sarı D. Hemşirelik Yüksekokulu Öğrencilerinin klinik öğrenim çevrelerini değerlendirmelerinin incelenmesi [Yüksek Lisans Tezi]. İzmir, TC Ege Üniversitesi Sağlık Bilimleri Enstitüsü, 2001.

10. Brynildsen G, Bjork IT, Bernsten K, Hestetun M. Improving the quality of nursing students' clinical placements in nursing homes: An evaluation study. Nurse Education in Practice 2014; 14:722-728.

11. Westin L, Danielson E. Nurses experiences of caring encounters with older people living in swedish nursing homes. International Journal of Older People Nursing 2006; 1:3-10.

12. Aud MA, Bostick JE, Marek KD, McDaniel RW.
Introducing baccalaureate student nurses to gerontological nursing. Journal of Professional Nursing 2006; 22:73-78.

13. Killam LA, Mossey S, Montgomery P, Timmermans K. First year nursing students' viewpoints about compromised clinical safety. Nurse Education Today. 2013; 33 (5): 475480.

14. Levett-Jones T, Pitt V, Courtney-Pratt H, Harbrow $\mathrm{G}$, Rossiter R. What are the primary concerns of nursing students as they prepare for and contemplate their first clinical placement experience?. Nurse Education in Practice 2015; $1-6$.

15. Hosoda Y. Development and testing of a clinical learning environment diagnostics inventory for baccalaureate nursing students. Journal of Advanced Nursing 2006; 56 (5): 480-490.

16. Chuan OL, Barnett T. Student, tutor and staff nurse perceptions of the clinical learning environment. Nurse Education in Practice 2012; 12 (4), 192-197.

17. Walton J, Blossom H. The experience of nursing students visiting older adults living in rural communities. Journal of Professional Nursing 2013; 29 (4): 240-251.

18. Smith JS, Barry DG. An Innovative approach to preparing nursing students for care of the elderly in the home. Geriatric Nursing 2013; 34:30-34.

19. Lea E, Marlow A, Bramble M, Andrews S, Eccleston C, McInerney F, Robinson A. Improving student nurses' aged care understandings through a supported placement. International Nursing Review 2015; 62: 28-35.

20. Carlson E, Idvall E. Who wants to work with older people? Swedish student nurses' willingness to work in elderly care-A questionnaire study. Nurse Education Today 2015; 35:849-853.

21. Skaalvik MW, Normann HK, Henriksen N. Clinical learning environment and supervision: experiences of Norwegian nursing students - a questionnaire survey. Journal of Clinical Nursing 2011; 20: 2294-2304.

22. Connell SE, Yates P, Barrett L. Understanding the optimal learning environment in palliative care. Nurse Education Today 2011; 31: 472-476.

23. Brown J, Nolan M, Davies S, Nolan J, Keady J. Transforming students' views of gerontological nursing: Realising the potential of 'enriched' environments of learning and care: A multi-method longitudinal study. International Journal of Nursing Studies 2008; 45: 1214-1232. 